Summary This study evaluated the effects of voltage changes on beam patterns of low-beam headlamps. Seven different types of filament lamps were tested. The voltages used were $12.0,12.8$ and $13.5 \mathrm{~V}$. The photometry was performed from $20^{\circ}$ left to $20^{\circ}$ right, and from $5^{\circ}$ down to $5^{\circ} \mathrm{up}$, all in steps of $0.5^{\circ}$. The main finding of this study is that, for all seven lamps tested, voltage changes between $12.0 \mathrm{~V}$ and $13.5 \mathrm{~V}$ caused light output to change by the same proportion throughout the beam pattern. Therefore, for filament lamps, it is reasonable to use a single constant for all values in a beam pattern when converting a headlighting specification at one voltage to a specification at a different voltage, at least if the voltages in question are between $12.0 \mathrm{~V}$ and $13.5 \mathrm{~V}$. The constants obtained across the seven lamps tested were similar to each other. Furthermore, these constants were in general agreement with the constants derived using the standard IES formula relating light-outut changes to voltage changes.

\title{
Do changes in voltage result in proportional changes throughout headlamp beam pattern?
}

\author{
M Sivak $\mathrm{PhD}$, M J Flannagan $\mathrm{PhD}$, E C Traube and T Miyokawa \\ The University of Michigan Transportation Research Institure, 2901 Baxter Road, Ann Arbor, MI 48109-2150, USA
}

Received 9 September 1998, in final form 14 Novernber 1998

\section{Introduction}

Photometric patterns of low-beam headlamps are not homogeneous ${ }^{(1)}$. Instead, there is a deliberate attempt to maximise illumination (and thus visibility) in certain parts of the pattern, and to minimise illumination (and thus glare) in other parts of the pattern. Furthermore, the visibility and glare portions of the beam partern are in close proximity. (In some parts of the beam pattern they are within $1^{\circ}$ of visual angle.) Inhomogeneity of the beam pattern is essential for proper performance of low-beam headlamps, and this must be maintained under the conditions in which the headlamps are operated (e.g. dirt, vibration, changes in voltage).

Reduction of the built-in inhomogeneity of the beam pattern must therefore be ruled out when changes in test voltage are being considered. Such changes in voltage would be needed to harmonise the currently disparate test voltages in different parts of the world. Thus, the specific question of interest is as follows: Do changes in voltage result in changes that are proportional throughout the beam pattern? If the answer is ' $y$ es', then a standard written for a given voltage (say $12.8 \mathrm{~V}$ ) could easily be converted to an equivalent standard at another voltage (say $13.5 \mathrm{~V}$ ) by multiplying all values by a single constant. If the answer is " $\mathrm{no}$ ", then no such simple conversion would be possible.

The proportionality that we are discussing concerns whether changes at two or more points in the bearn pattern are proportional to each other, not whether any of the changes in light output are proportional to voltage. According to the IES Lighting Handbook ${ }^{(2)}$, light output changes for filament lamps are related to changes in voltage by the formula $\left(V_{2} / V_{1}\right)^{3.4}$. For example, if the new voltage $\left(V_{2}\right)$ is $13.5 \mathrm{~V}$, and the old voltage $\left(V_{1}\right)$ is $12.8 \mathrm{~V}$, then to obtain the light output at $13.5 \mathrm{~V}$ one should multiply the light output at $12.8 \mathrm{~V}$ by $\left.1.198\left[(13.5 / 12.8)^{3.4}=1.198\right)\right]$.

Sivak et al ${ }^{(3)}$ evaluated, for a representative sample of 35 US low-beam headlamps, changes in light output at one test point $(\mathrm{H}, \mathrm{V})$ as a function of test voltage between $12.0 \mathrm{~V}$ and $13.5 \mathrm{~V}$. The results indicated that the light-output changes were in good agreement with the IES formula. However, Sivak et al. ${ }^{(3)}$, by evaluating the changes at one test point only, were not able to address the issue of proportionality of light-output changes throughout the beam pattern.

One reason why voltage changes could lead to nonproportional changes in light output is that, as the voltage is increased, a larger section of the filament might emit visible radiation. Consequently, because the optical control for a given lamp is designed with respect to a given size of a filament that is emitting visible radiation, a change in the size of the 'active' filament might lead to deviations from proportionality. If there is, indeed, sufficient change in the size of the active filament to result in deviations from proportionality, then the presence of an internal shield (which certain types of lamps use to limit light output above the horizontal) might increase this effect.

The present study was designed to evaluate the effects of voltage changes on low-beam patterns of seven major types of filament lamps currently in use in the USA, including one with an internal shield. Detailed photometric matrices were obtained for three different test voltages $(12.0,12.8$ and $13.5 \mathrm{~V}$ ).

\section{Method}

\subsection{Approach}

The beam partern of each of seven low-beam headlamps was measured at three voltages: $12.0,12.8$, and $13.5 \mathrm{~V}$.

\subsection{Lamps}

The lamps tested were selected to include the major types currently in use in the USA ${ }^{(2)}$. Table 1 describes the lamps tested. The lamps were purchased at car dealerships.

\subsection{Photometry}

We determined the luminous intensities at 1701 test points in a rectangular matrix defined by the following horizontal and vertical angles (in relation to the headlamp axis). In the horizontal direction, the angles ranged from $20^{\circ}$ left to $20^{\circ}$ right in steps of 0.5 . In the vertical direction, the angles ranged from $5^{\circ}$ down to $5^{\circ}$ up in steps of $0.5^{\circ}$. 
Table 1 The lamps used in the study and their construction

\begin{tabular}{llll}
\hline $\begin{array}{l}\text { Label in this } \\
\text { paper }\end{array}$ & Bulb type & Internal shield & Optical control \\
\hline 9004 & $9004(\mathrm{HB} 1)$ & No & Lens \\
H4 & H4 (HB2) & Yes & Lens \\
9006 & $9006(\mathrm{HB} 4)$ & No & Reflector \\
Projector & $9006(\mathrm{HB} 4)$ & No & Projector \\
9007 & $9007(\mathrm{HB} 5)$ & No & Reflector \\
H7 & H7 & No & Lens \\
Sealed bearn & Sealed beam (H6054) & No & Lens \\
\hline
\end{tabular}

All measurements were made in the same photometry laboratory.

\subsection{Procedure}

There are six possible orders of the three test voltages. In order to balance the effect of order, five of these orders were used for each of five lamps, and one order was used for two lamps.

Each headlamp was seasoned at $12.8 \mathrm{~V}$ for one hour a few days before the actual photometry. The three photometry sessions (one for each voltage) were performed on the same day. Immediately prior to the first photometry session, the tested lamp was seasoned for an additional 30 minutes using the first test voltage. Immediately prior to each of the other two photometry sessions, the lamp was seasoned for an additional 5 minutes using each of the respective voltages.

\section{Results}

The effects of voltage on luminous intensities were very well described by linear functions with zero intercepts $(y=a x)$. (The best-fitting lines with zero intercepts originate in the $(0,0)$ point, and thus make more theoretical sense than those with nonzero intercepts. However, the lines with and without zero intercepts were virtually identical. The differences in slopes, if any, were in the third decimal place.) The variance accounted for in each case was $99 \%$ or greater. Table 2 lists the slopes of these best-fitting linear functions and compares them with the predictions derived from the IES formula. Typical data are shown in Figures 1 and 2 for one of the seven lamps tested (9007). Figure 1 compares the luminous intensities at $12.8 \mathrm{~V}$ with those at $12.0 \mathrm{~V}$ at each of the 1701 test points. Analogous information for the test voltages of $13.5 \mathrm{~V}$ and $12.8 \mathrm{~V}$ is shown in Figure 2.

\section{Discussion}

The main finding of this study is that for all seven filament lamps tested the effects of voltage changes in the range from

Table 2 Slopes of the best-fitting linear equations with zero intercepts

\begin{tabular}{lll}
\hline Lamp & $12.8 \mathrm{~V}$ vs. 12.0 V & $13.5 \mathrm{~V}$ vs. 12.8 V \\
\hline 9004 & 1.225 & 1.188 \\
H4 & 1.233 & 1.217 \\
9006 & 1.263 & 1.211 \\
Projector & 1.239 & 1.171 \\
9007 & 1.248 & 1.169 \\
H7 & 1.221 & 1.181 \\
Sealed beam & 1.235 & 1.215 \\
Mean & 1.238 & 1.193 \\
Using the IES formula & 1.245 & 1.198 \\
\hline
\end{tabular}

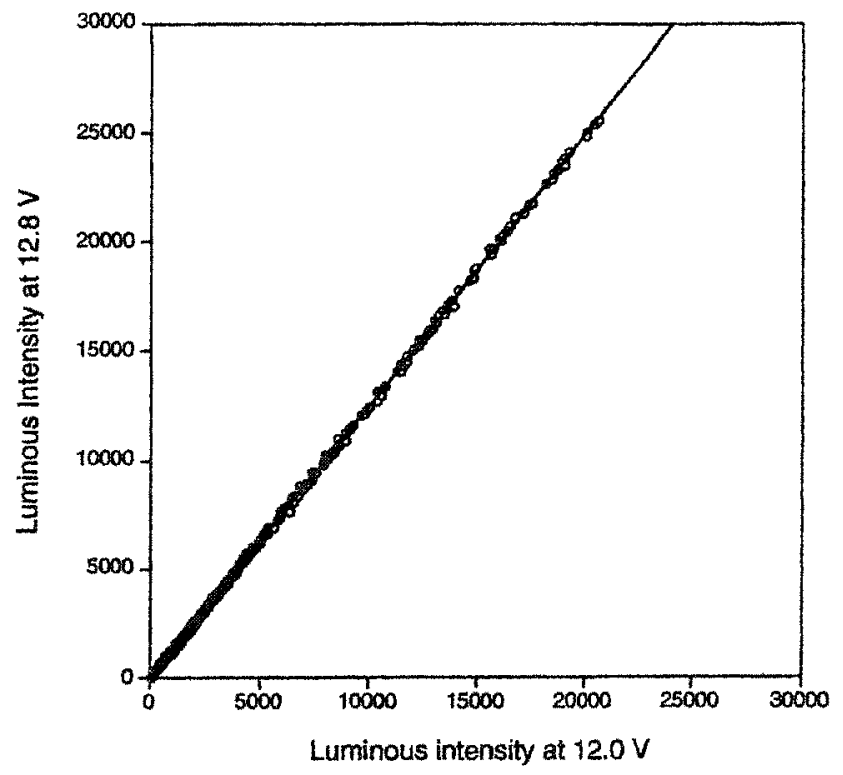

Figure 1 Luminous intensities (in cancela) at $12.8 \mathrm{~V}$ and $12.0 \mathrm{~V}$ for the 9007 lamp

$12.0 \mathrm{~V}$ to $13.5 \mathrm{~V}$ were well described by linear functions with no intercepts. This finding implies that voltage changes between $12.0 \mathrm{~V}$ and $13.5 \mathrm{~V}$ tended to result in proportional changes in light output throughout the beam pattern. Therefore, for filament lamps, it is reasonable to use a single constant for all values when converting a headlighting specification at one voltage to a specification at a different volrage, at least if the voltages in question are between $12.0 \mathrm{~V}$ and $13.5 \mathrm{~V}$.

The constants obtained across the seven lamps tested were similar to each other. (For each of the two pairs of voltages, the difference between the lowest and highest constants was less than $4 \%$.) Furthermore, these constants were in general agreement with the constants derived by using the standard IES formula relating light-output changes to voltage changes. (For each of the two pairs of voltages, the differ-

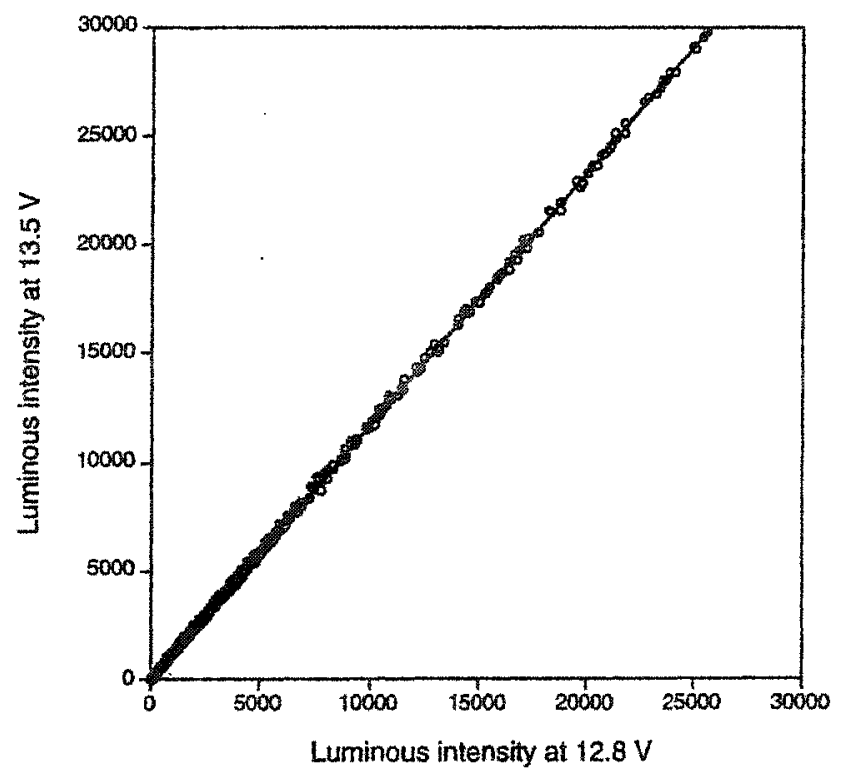

Figure 2 Luminous intensities (in candela) at $13.5 \mathrm{~V}$ and $12.8 \mathrm{~V}$ for the 9007 lamp 
ence between the mean for the seven lamps and the value derived using the IES formula was less than $1 \%$.)

The present findings suggest that the light-emitting part of the filament does not change appreciably with changes in voltage between $12.0 \mathrm{~V}$ and $13.5 \mathrm{~V}$. Furthermore, because the data for the one test lamp with an internal shield (an H4 lamp) did not differ from those for the other six lamps, the findings suggest that the presence of an internal shield does not necessarily lead to nonproportional changes in light output with changes in voltage.

\section{Acknowledgements}

Appreciation is extended to the members of the University of Michigan Industry Affiliation Program for Human Factors in Transportation Safety for support of this research. The current members of the Program are Adac Plastics, BMW, Bosch, Britax International, Corning, DaimlerChrysler, Denso, Federal Mogul Lighting
Products, Ford, GE, GM NAO Safety Center, Guide Corporation, Hella, Hewlett-Packard, Ichikoh Industries, Koito Manufacturing, LESCOA, Libbey-Owens-Ford, Magneti Marelli, North American Lighting, Osram Sylvania, Philips Lighting, PPG Industries, Reflexite, Reitter \& Schefenacker, Stanley Electric, Stimsonite, TEXTRON Automotive, Valeo, Visteon, Yorka, 3M Personal Safety Products, and $3 M$ Traffic Control Materials.

\section{References}

1 Sivak $M$, Flannagan $M J$ and Sato $T$ Light output of U.S., European, and Japanese low-beam headlamps Transportation Research Record 1456 99-111 (1994)

2 IES lighting handbook, Reference volume (New York: Illuminating Engineering Society) (1984)

3 Sivak $M$, Flannagan $M J$, Kojima $S$ and Traube E $C A$ market-weighted description of lowv-beam headlighting patterns in the US SAE Technical Paper Series 980317 (Warrendale, PA: Society of Automotive Engineers) (1998) 